Article

\title{
Study on the Sustainable Development of Human Settlement Space Environment in Traditional Villages
}

\author{
Hai-fan Wang ${ }^{1,2, *}$ and Shang-chia Chiou ${ }^{1}$ \\ 1 Graduate School of Design, National Yunlin University of Science \&Technology, Yunlin 64002, Taiwan \\ 2 School of Art and Design, Taizhou University, Taizhou 318000, Zhejiang, China \\ * Correspondence: D10730024@yuntech.edu.tw; Tel.: +886-965-642-484
}

Received: 28 May 2019; Accepted: 30 July 2019; Published: 2 August 2019

\begin{abstract}
The sustainability of the human settlement space environment is an eternal subject of human exploration. There hides the idea of human settlement space in an externally displayed material environment. This paper takes Dai villages in Xishuangbanna, Yunnan as the research object. Dai villages are the place where the ancestors of Dai people live, produce, and collectively construct human settlement, production, and spirit. Taking field investigation data and maps of Dai settlement areas as data sources, this paper explores Dai people's view of human settlement space, analyzes the spatial cultural connotation of Dai villages, and the concept of sustainable human settlements ecology through the analysis of the factors of the villages' spatial form. The survey results are as follows: (1) the villages are usually located at river valleys and basin areas, which are characteristic of facing the sun and near the water, embodying the persevering ecological concept of "adapting to local conditions and coexisting with nature". (2) Dai people are one of the earliest "rice-growing nationalities". Dai people's settlements have formed a sustainable human settlement ecological space and the spatial pattern of "water-forest-field-village" is an organic whole. (3) The combination of Dai's primitive religious ecology and Southern Buddhist culture has formed the characteristic of "advocating nature and Buddhism" and a unique concept of settlement space.
\end{abstract}

Keywords: Dai villages; ecological environment; sustainable development; human settlement space

\section{Introduction}

Village is the basic way of human existence. Traditional villages are ancient villages and towns which have relatively complete ancient houses, traditional customs and lifestyles, as well as minority villages with ancient buildings and peculiar customs [1]. The spatial form of Dai villages is a long-term evolution. The way to maintain the affinity with nature is to respect, revere, and integrate nature in the long historical process, and to continue the sustainable ecological values spread by the ancestors. Previous studies on Dai villages often paid too much attention to the study of residential architecture, spatial form, and architectural technology. In this paper, the whole system of villages is used to analyze the connotation of residential space environment from the whole system to elements. Using case-based research methods, with field investigation and field mapping, combined with local literature, Manla village, Manbie village, and Manting village were used as case studies. This paper analyzes the influence of geographical and climatic conditions, natural environment, religious and cultural diversity on the village, attaches importance to the influence of multi-composite unity and the social and cultural environment, and analyzes the connotation of the spatial environment of Dai village from three aspects: spatial development, constituent elements, and cultural characteristics of the village.

Dai villages contain profound cultural connotations in site selection, composition, material, and non-material space interaction. By summarizing and comparing the ecological environment of human settlement of Dai nationality, this paper discusses the mechanism of its occurrence and development 
as well as the ecological concept of human settlement, and explores the evolution mode and cultural connotation of the villages and means to provide references for the phenomenon of "same images of the village", "same images of the town", and the suitability of human settlements in the process of urbanization in modern society. The main purpose of the study is to analyze the characteristics of the ecological space of human settlement in Dai villages and to discuss its cultural connotation and sustainable strategies. (1) The cultural characteristics of the ecological environment of the traditional Dai villages. It is mainly reflected in the remarkable characteristics of the village cultural contexts constructed by cultural integration. (2) Providing theoretical references and strategic suggestions for the environmental protection and sustainable development of Dai traditional human settlements. The present situation of traditional Dai villages is worrying. The impact comes from two aspects. One is the improper entry of commercial interest groups which has brought some negative effects to the protection of villages during the development of tourism. The other is that a large number of residents moved out from the villages, resulting in the hollowing-out of village interior, making the villages lose vitality of development in the past. (3) The enlightenment to the urbanization in modern society is mainly reflected in the site selection of urban and rural areas, cultural inheritance of traditional villages, and the protection of the creativity of residential subjects.

In summary, Dai village reflects the residents' living habits, religious worship, aesthetic psychology, and cultural values. Exploring the future development of ethnic villages, excavating and absorbing its reasonable and high-quality genes, seeking the cultural spirit of traditional villages and characteristics of material presentation are the contributions of this research.

This study takes Xishuangbanna Dai Autonomous Prefecture (Figure 1), Yunnan, China, as the research object and the scope of data collection. Xishuangbanna is located between $21^{\circ} 08^{\prime} \mathrm{N}$ and $22^{\circ} 36^{\prime} \mathrm{N}$ and $99^{\circ} 56^{\prime} \mathrm{E}$ and $101^{\circ} 50^{\prime} \mathrm{E}$. It borders Laos and Myanmar in the southeast, south, and southwest, respectively. There are Jinghong city, Menghai county, and Mengla county.

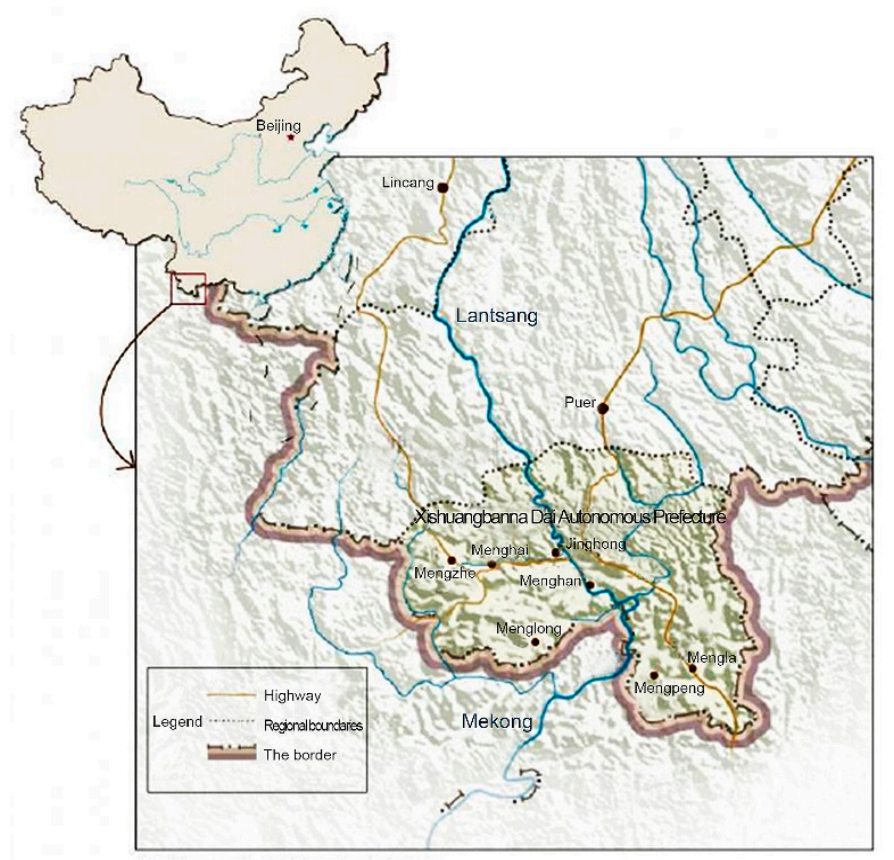

Figure 1. Xishuangbanna Dai autonomous prefecture.

The light source is sufficient. The annual sunshine hours are 1500-2200 hours, and the total solar radiation is measured at $120-135 \mathrm{kcal} / \mathrm{cm}^{2}$. The state is rich in caloric resources, and the winter is warm, the summer is rainy and not hot, the terrain is inversion. The annual average temperature of the whole state is $15.1-21.8^{\circ} \mathrm{C}$. The annual temperature difference is small, generally $9.1-10.4{ }^{\circ} \mathrm{C}$ (Table 1 ). 
Table 1. Table of Air Temperature in Xishuangbanna $\left({ }^{\circ} \mathrm{C}\right)[2]$.

\begin{tabular}{ccccc}
\hline Place & $\begin{array}{c}\text { Altitude } \\
\text { (Meters) }\end{array}$ & $\begin{array}{c}\text { Average } \\
\text { Temperature }\end{array}$ & $\begin{array}{c}\text { Average Hottest Monthly } \\
\text { Temperature }\end{array}$ & $\begin{array}{c}\text { Average Coldest Monthly } \\
\text { Temperature }\end{array}$ \\
\hline Jinghong & 553 & 21.8 & 25.7 & 15.7 \\
Mengla & 632 & 21.1 & 24.6 & 15.2 \\
Menghai & 1176 & 18.2 & 22.3 & 11.9 \\
\hline
\end{tabular}

The state has abundant rainfall with distinct rainy and dry seasons. The precipitation in the wet season accounts for $82-85 \%$ of the total annual precipitation. The annual precipitation ranges from $1138.6 \mathrm{~mm}$ to $2431.5 \mathrm{~mm}$. The monthly precipitation in July-August is more than $250 \mathrm{~mm}$. The minimum precipitation in February is only $20 \mathrm{~mm}$. The annual average of relative humidity in all parts of the state ranges from $78-88 \%$. The precipitation in the dry season is less but foggy (the foggy days are generally 131.7-152.7), which raises the humidity in the dry season and compensates for the lack of precipitation to a certain extent [3]. Xishuangbanna is a tropical humid area to the south of the Tropic of Cancer. It has a unique geographical location and topography, which gives the area large solar radiation, long sunshine, abundant light energy, and abundant heat.

Manla village, Manbie village, and Manhai village in Xishuangbanna are selected as specific research objects. The author has visited the area many times since 2010. The research sites above are typical Dai villages, and the spatial texture and ecological environment are preserved intact, which provides a good field investigation sites for this study.

\section{Literature Review}

Academic circles generally believe that the study of traditional Chinese dwellings began in the 1930s, with the investigation of ancient architecture of Society for the Study of Architecture. The Journal of the Society of Architecture of China recorded the surveying and mapping of traditional buildings in Yunnan. Liu (1941) published a survey of ancient buildings in southwest China, which was recognized as the pioneer of the study of Chinese dwellings. Research in this period, taking residence as a type of traditional Chinese architecture, had no discussion on the human settlement environments from the overall perspective of architectural groups or settlements. In 1957, Overview of China's Housing was published, which raised the residential architecture to a new status. Since then, the research on residential architecture has been paid attention to by the national architectural circles [4]. From the 1950s to the 1980s, theoretical achievements in the study of minority villages in southwestern China were published, such as Dwelling Houses in Yunnan and History of Ancient Chinese Dwellings and so on. The Yunnan Folk House compiled by Yunnan Design Institute in 1986, discussed the natural and social profiles of Dai settlements in China. Divided by type, it falls into three categories: Xishuangbanna Dai dwellings, Dehong Ruili Dai dwellings, and Dehong Luxi Dai dwellings, which were discussed separately. In the 1990s, with the development of research methods and cross-disciplinary research, the ethnic villages in southwest China have been systematically studied. Scholars such as Zhu, Chen, Jiang, Dai, and Yang have focused on the traditional ethnic villages in Yunnan. At this stage, the study of Yunnan's dwellings mostly focuses on the introduction of specific regions, focusing on the measurement of single building, the description of flat facade, structure, and decoration. There is a lack of discussion on organization and planning of settlement space, the construction order and method, and the construction concept behind it. From the year 2000 to the present, the research on the folk dwellings has begun to enter into multi-angle and multi-discipline comprehensive research, and the research on the folk dwellings mainly includes the following four aspects: (1) combine the study of residential houses with social, cultural, and philosophical ideas, (2) combine residential research with form and environment, (3) the study of residential houses is combined with the creation and design, and (4) pay attention to the protection, transformation, and renewal of traditional villages. Research achievements in this period include: Yunnan Vernacular Architecture Culture, Chinese Folk Houses, From Traditional Folk Houses to Regional Buildings etc. [4]. 
Research on villages from the perspective of anthropology and ethnology enriches the methods and perspectives of traditional village research. Research methods such as field investigation, observation, and interview are widely used. Malinowski, the advocate of anthropological functionalism, laid the foundation for anthropological research on the long-term fieldwork of Trobriand. Traditional village research applies methods of anthropology for long-term field research to obtained the first-hand information at that time. In 1881, Lewis Henry Morgan, an American anthropologist, published The House Architecture and Family Life of the Indians, introducing settlements and houses constituting settlements into cultural anthropology, and exploring the formation and development of settlements at a deeper level. For the study of settlements in residential areas, Morgan's analysis of the social structure and its evolution has theoretical significance [5]. Vogt believes that the study of settlement morphology distribution should be carried out from the following five aspects: (1) nature of the individual house, (2) spatial arrangement of these houses within a village or community unit, (3) relationship between houses and other buildings such as temples, palaces, sports fields, festivals, etc., (4) village or community entire floor plan, and (5) spatial relationship between a village or community and other villages or communities within a particular area. In general, ethnic scholars divide settlement units into three floors, that is, individual buildings, within villages, and between villages [6]. Jiang did a detailed research on Dai's history, culture, society, and other aspects: Dai villages are near the water, beside streams, and on both sides of rivers. There must be Dai villages in the place which is surrounded by green trees [7]. Study on the Hakka village Form System and Residential Model: On the one hand, it studies the historical period of Hakka architecture, on the other hand, it discusses the relationship between Hakka architecture-type systems and social culture, and studies the analysis of "category", "type", and "period" of Hakka architecture culture. In addition, works such as Southwest National Architecture Research, Exploration of Architectural Culture of Yi Nationality, Studies on the Forms and Culture of Ethnic Minorities in Yunnan, and Yunnan National Housing Culture are exploring ethnic architecture from the perspective of ethnology. Yang (2004) incorporated Dai villages in southwest China into the Southeast Asian architectural culture circle, and compared with Southeast Asian architecture, which is a good reference for the future study of Dai villages [8]. Liu discussed Dai's cognition of nature from the perspective of ecological thought and explored the significance of Dai's ecological environment thought and a series of problems that existed and were faced in the context of modernization [9]. To sum up, the concept of culture runs through the main line of the study. The study from the perspective of anthropology and ethnology pays more attention to the influence of regional cultural diversity, social phenomena, economic forms, and political systems on village changes.

From the perspective of human settlements environment science, the study of villages pays attention to the layout and spatial analysis of villages. In the Encyclopedia of Vernacular Architecture of the World, published in 1997, the author gives a comprehensive account of local architecture in different parts of the world, and explores the research methods of local architecture from multiple perspectives and fields [10]. Wang believed that the imitation and analogy of the prototype played an important role in the growth of traditional villages. The imitation maintained the order from settlement to community, while the analogy brought variation and renewal to the settlement form in the process of settlement and migration. Gao brought Dai dwellings into the Southeast Asian dwelling system and analyzed the different tracks of Dai villages in the development in Xishuangbanna and Dehong. She discussed the reflection of the traditional social structure of Dai nationality in the spatial distribution of dwellings and analyzed the impact of modernization processes on Dai villages [11]. Wang took the spatial form and ecological culture of Dai traditional settlements as the object and discussed the general characteristics of Dai traditional settlements and architectural spatial form from the aspects of geographical region, cultural spirit, and time dimension, and summarized the spatial environment and architectural spatial structure connotation of Dai traditional settlements [4]. Liu studied the characteristics of Dai dwellings and village layout under the influence of climate, geographical environment, and Dai folk culture. Wang explained the spatial location, spatial layout, and the shape of residential buildings of Dai villages from the perspective of plastic arts and spatial 
composition. Fang took 19 traditional villages in Hainan Island as the research objects and used field investigation to analyze and study the site selection characteristics, evolution law, spatial layout, shape and structure of residential buildings, plant composition, and application of the traditional villages in Hainan. Shen tried to find out the commonness and characteristics of the spatial composition of traditional Dai dwellings through the analysis of typology, and further understand the evolution mode and essential reasons of these architectural features. The research on Dai villages tends to change from single building to whole villages. At the same time, using interdisciplinary research methods, the research angle is more diversified, and the protection of Dai villages has also been paid more attention.

The relationship of villages is studied from the perspective of religious studies and spiritual fields. Huang explored the origin of nationality in detail and found that Dai nationality belonged to the southern Buddhist cultural area [12]. Zhu discussed the relationship between Dai villages and beliefs from the perspective of primitive religious beliefs and revealed that the influence of primitive religious beliefs on villages was the carrier of collective beliefs. Schulz pointed out that the place should have "spirituality", which is a whole composed of specific substances. It is a sense of belonging and identity to a place for a village where people are closely interacting with each other. From the perspective of people, paying attention to people's spiritual feelings is the significance of the inheritance and development of the traditional village space [13]. Fu explored the relationship between Dai's religious concepts and buildings as well as villages from the primitive religious level and constructed three levels from architecture and villages to religious consciousness. The layout and space of the villages were sanctified through a series of religious rituals and symbols, connecting it with sanctity [14]. Wang discusses the influence of religious consciousness on Dai villages and explores the evolution of Dai villages from natural factors to religious factors. The spatial environment of Dai villages is influenced by natural environment, primitive religious beliefs, and Southern Buddhism. Especially, Southern Buddhism is a new perspective for the study of Dai villages, architectural forms, and spatial philosophy. For example, Dai people's space concept is "square", there are four village gates in Dai people's villages, Dai residential buildings are square bamboo buildings, and Buddhist temples are square buildings. The external form of these buildings and culture are in one continuous line.

In summary, the research on Dai villages has shifted from the study of single buildings to human settlements, from single subject analysis to multidisciplinary integration, and the cognitive scope ranges from material and non-material to overall research development programs. However, the research angle is relatively scattered and isolated, so a holistic and systematic research framework is set up to sort out the relationship between various cultural elements more clearly and establish the relationship with villages, which is particularly important for the study of Dai people's living space environment [15].

\section{Research Methods and Process}

\subsection{Research Methods}

\subsubsection{Field Investigation}

Field investigation is a common method in anthropology. The spatial study of anthropological ethnography is rooted in three important aspects: geography, the blood, and human behavior patterns. Anthropological research on space, is really regarded as a theory starting from E. Durkheim. E. Durkheim and M. Mauss believe that space, time, numbers, causality, etc., are the most basic classification concepts of every society: the entire knowledge system of a society is developed from these basic classification concepts [16]. This study used the method of anthropological ethnography to conduct in-depth research in Jinghong and Menghai and collected data through records and interviews.

Ethnography and fieldwork are inseparable. "The rules of ethnographic compilation restrict the scope, content, and methods of field investigations, affecting the depth and breadth of fieldwork, and ultimately determine the authenticity and scientific nature of ethnography" [17]. The main characteristics of anthropological ethnography research are holism, which is manifested in two aspects: 
Firstly, ethnography generally adopts a panoramic description, which comprehensively introduces and analyses the social organization, cultural customs, religious beliefs, mythology, and art of the object of study, and elaborates the relationship between each part and the whole. Secondly, the object of study usually appears as a collective image [18]. This paper uses the field survey method to obtain data, to understand and grasp the local reality as much as possible, and to provide a reliable realistic basis for the study. With a long period of field observation, villagers' livelihood would get a detailed understanding and experience the various aspects of livelihood changes in the process of participation and observation. According to different situations in the actual communication with villagers, the full use of structured, semi-structured, and non-structured interviews can enrich the first-hand information of field investigation.

From July 27 to August 12, 2018, the author investigated Manla village, Menghai, Xishuangbanna Dai Autonomous Prefecture. Through interviews, participatory observation, surveying, and mapping, the author understands the development of Manla village. Manla village is a Dai nationality, with a total of 100 households and 515 people. It is located in the valley and basin area, along the river, and the residential buildings are distributed along the topography. The temple is located in the center of the village, which is the spiritual center of the village residents' communication. The human settlement environment has gone through the process of wooden structure grass roof, wooden structure, bamboo, gray tile, and brick and concrete structure. The habitat environment has gone through three stages. In the first phase, before the 1990s, the architectural form was a combination of wooden structure framework and bamboo weaving. In the second phase, in the 1990s, the villagers of Manla gradually moved to the present location of the village. The building shape was wooden structure, and the single building was a two-story wooden structure of 16 meters times 16 meters. The third phase is the beginning of the 21 st century. Take the village head's residential house as an example, the house was built in 2007 as a brick-concrete structure. The survey also included economic income sources mainly from cash crops such as tea and rubber. In particular, Pu'er tea increased economic income, and most families gave birth to two children. In the actual investigation, the author found that Dai nationality in Xishuangbanna is a multi-dimensional space constructed by a single ethnic group and formed by the interaction of the natural environment, the social environment, the production environment, the cultural environment, and national beliefs. Dai people's living environment is both natural and social, including human habitat, production field, and spiritual field.

\subsubsection{Interviews}

Interviews are based on pre-set questions to obtain and understand the cognition of interviewees. In this study, interviews were conducted in an open and individual way, and interview data were analyzed by means of "verbatim transcription". The interviewees were divided into introduction and random interviews. The targeted interviews refer to elders who are familiar with Dai nationality, such as Xue Ai, Yan Ai and Wen Ai in Manla village and the random interviews are interviews in which the right subjects are randomly selected at the research site. The main content of the interviews was the historical development, ethnic beliefs, social structure, spatial form, and national culture of villages. The author has continuously paid attention to the sustainable development of Dai people's traditional living space environment in Xishuangbanna and has made long-term observations of Dai villages in Xishuangbanna. From 9 to 17 June 2010, 1 to 15 September 2011, and 25 October to 14 November 2012, the author visited Ganlanba, Manjiang village, and Manbie village in Xishuangbanna. From 12 to 26 October 2015, and 7 to 19 July 2018, the author visited Manting village, Manbie village, and Manla village for further research. The research focuses on semi-structured interviews through the "snowball" sampling method. The interviews have four levels: (1) In-depth interview with key figures. The key figures are mainly government staff, which will help to obtain the development policies of the living environment of Dai villages. (2) Interview with traditional craftsman. As front-line workers, they have an accurate understanding of the ways and techniques of village construction. (3) Interviews with local residents to understand changes in the local living environment. (4) Visitors' interviews reveal their 
views on the development and culture of traditional villages. The interviews included the development process, construction features, architectural structure, and living style of the villages. A total of 57 key interviewees were interviewed for more than 1 hour, and anonymous coding was carried out in the later stage. From 2015 to 2018, there were 22 key interviewees (Table 2). The interview data in this paper are coded as 20151112CVN-I, the first eight are interview years and dates, " $C$ " means survey city, "JH" means Jinghong, "MH" means Menghai, "ML" means Mengla, "V" means survey village, and "GLB" means Ganlanba. "MJ" means Manjiang, "MT" means Manting, "MB" means Manbie, "ML" means Manla, etc., " $\mathrm{N}$ " means the number of interviewees, "I" means the identity of interviewee, " $\mathrm{A}$ " means government staff, " $\mathrm{B}$ " traditional craftsman, " $\mathrm{C}$ " means local resident, and " $\mathrm{D}$ " means tourist. For example, "20151012JHMT01-C" represents the first interviewee in Jinghong Manting, 10 June 2015, whose identity is a local resident. Secondly, the author participated in the traditional village designs. Through discussions with colleagues and customer feedback, the author has a certain understanding of the traditional village culture and construction, and a comprehensive understanding of the Dai people's living environment development.

Table 2. Survey interview samples.

\begin{tabular}{ccccc}
\hline Number & Gender & Age & Occupation Status & Usual Residence \\
\hline 20151012JHMT01-R & F & 36 & Farmer & Manting \\
20151013JHMT02-A & M & 52 & Farmer & Manting \\
20151014JHMT03-G & F & 40 & Staff & Jinghong \\
20151016JHMT04-T & M & 25 & Staff & Jinghong \\
20151020JHMT05-G & M & 48 & Staff & Manting \\
20151020JHMT06-A & M & 70 & Staff & Manting \\
20151021JHMB07-R & M & 67 & Famer & Manbie \\
20151021JHMB08-R & F & 32 & Famer & Manbie \\
20151022JHMB09-G & M & 41 & Staff & Manbie \\
20151022JHMB10-T & M & 33 & Staff & Kunming \\
20151024JHMB11-G & M & 44 & Staff & Manbie \\
20151024JHMB12-R & F & 27 & Famer & Manbie \\
20151025JHMB13-A & M & 46 & Famer & Manbie \\
20151025JHMB14-R & M & 67 & Famer & Manbie \\
20180727MHML01-R & F & 55 & Famer & Manla \\
20180727MHML02-R & M & 40 & Famer & Manla \\
20180728MHML03-G & M & 46 & Staff & Manla \\
20180728MHML04-A & M & 66 & Famer & Manla \\
20180729MHML05-G & M & 37 & Staff & Manla \\
20180729MHML06-R & F & 31 & Famer & Manla \\
20180729MHML07-R & M & 50 & Famer & Manla \\
20180802MHML08-A & M & 48 & Famer & Manla \\
\hline
\end{tabular}

\subsubsection{Investigation and Measurement of Village Form}

From 2011 to 2017, the mapping of several typical settlements in Jinghong (Manjiang, Manting, Manbie, etc.) was completed. In July 2018, the author participated in the "Lantsang-Mekong Ethnology and Anthropology Summer Course" and completed the mapping of Manla village through the exploration of actual space, recording the spatial layout of villages, the village gate, Buddhist temples, ancient trees, wells, etc., to understand the trajectory and behavior of Dai people in the village space.

\subsection{Research Process}

(1) Read books, literature, county annals, and folk customs of Dai people, etc. For example, Dai ethnographic texts include Manshu (Fan, Tang Dynasty), Yunnan Zhiluo (Li, Yuan Dynasty), Local Customs of Water Baiyi (Yao, 1938), Study of Baiyi in Western Yunnan (Jiang, 1939), Life Culture of Baiyi (published by China Book Bureau, 1950), and Data Series of Investigation of Social History of Chinese Minorities (revised editorial board, 1979) recorded the social, economic, and customs of Dai, 
which provided important information. Familiar with the academic trends of cutting-edge research, comprehensive and in-depth comparison and analysis, integration of data, discovery and put forward ideas, so as to establish the basic ideas and main objectives of the paper.

(2) Through interviews with Dai residents, in-depth understanding of Dai history and culture, human geography, traditional customs and other aspects of information, collect first-hand data, use in-depth interviews, rooted theory to collect and analyze data. Collated and integrated first-hand information such as field research, mapping drawings, pictures and interview records. On the premise of practical examples, combined with research, perception, and the study of historical materials, preliminary sorting and analysis were carried out, and opinions were put forward. For the missing materials, villages at the research sites were revisited to refine the problems and observe them. Consult village leaders, government officials and experts and constantly revise the research content.

(3) On the basis of comprehensive synthesis of Dai's current situation data, this paper obtained the status of Dai villages, straightened out the cultural context and causes, and carried out characteristic analysis. Through the growth mechanism and spatial composition of the traditional villages of Dai people, the cultural characteristics were analyzed, and the spatial characteristics of Dai villages were explored to reveal their hidden deep connotations. The cultural connotation of the space environment of Dai village dwelling was obtained, and the analysis of these causes has important implications for the protection of modern society's urbanization, rural tourism, characteristic towns, and ethnic cultural heritage.

\subsection{Research Framework}

The living space environment of Dai villages is influenced by both natural and artificial environmental factors. The natural environmental factors include climate, geography, rivers, etc.; and the human environmental factors include primitive beliefs, national customs, religious beliefs and so on. Through field research, interviews and surveys, this paper analyses the spatial layout and architectural structure of Dai villages. Through the research, it is found that Dai villages are the crystallization of the wisdom of Dai people, an integral system, plurality of ecological space environment constructed by a single nation, containing the harmonious coexistence of man and nature, and the primitive clan and the sustainable development concept of the integration of religion and Buddhism (Figure 2).

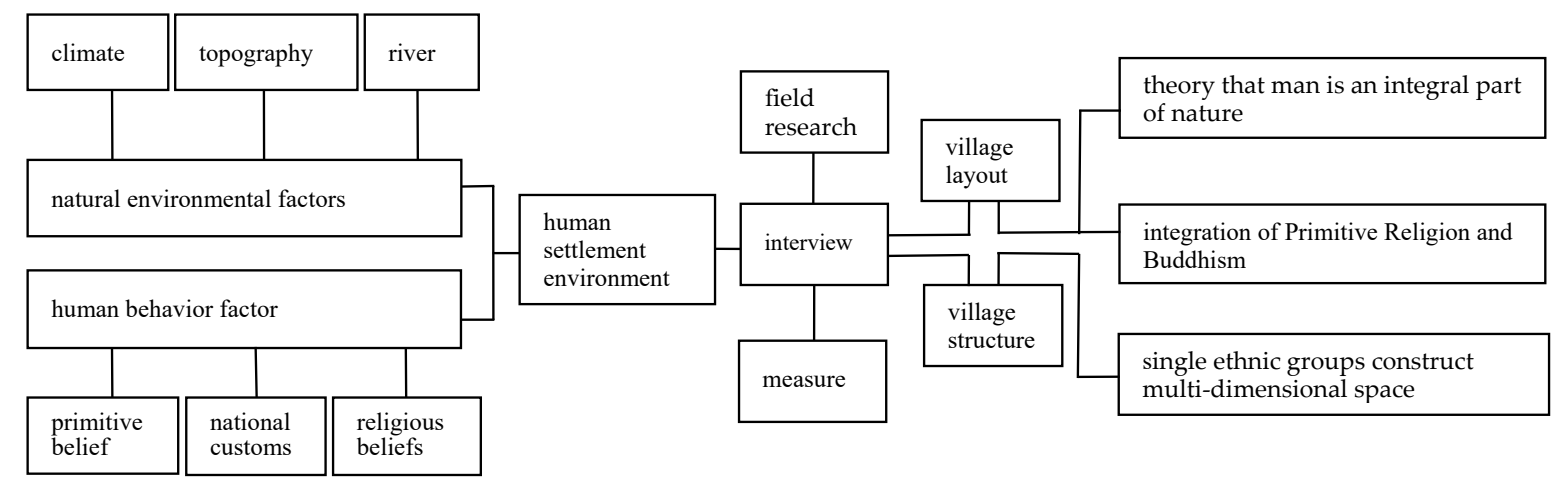

Figure 2. Exploring Dai settlement space.

\section{Discussion}

\subsection{Scientific Layout of Villages is Conducive to Production and Life}

\subsubsection{Rich Water Environment, Convenient Life}

"The foam floats with the waves, and Dai people follow the water. Dai people have a special preference for water". Water not only has the power to determine the way of production, but also the power to influence the national character. Dai people advocate that nature, mild personality, and 
friendliness are closely related to water. Dai people living in Xishuangbanna are called "Dai Le" in Dai language. Sangkangbimai (Water Sprinkling Festival) is the most grand and full ethnic festival of Dai people.

The relationship between Dai villages and rivers is mainly manifested in the construction along the rivers, which is convenient for irrigation and living. At the same time, the river defines the spatial scope. The rich water environment of Dai villages can be divided into three categories: (Figure 3) (1) larger rivers, where the village layout is determined by the river trend and the settlement space takes the river as the vein. For example, the settlement layout of the Olive Dam Dai Garden is built along the trend of Lantsang, (2) the pond, which spreads in the settlement space, is a self-contained system, (3) wells in the form of spots, that is, the main source of water for Dai residents and gives Dai villages a living scene of "under bamboo forests and near wells, Dai daughters are busy fetching water" [19]. The three kinds of water bodies are represented as points, lines, and planes in the village space environment, which constitute the rich and beautiful water environment of Dai settlements together and embody Dai culture of paying attention to ecology and respecting nature.

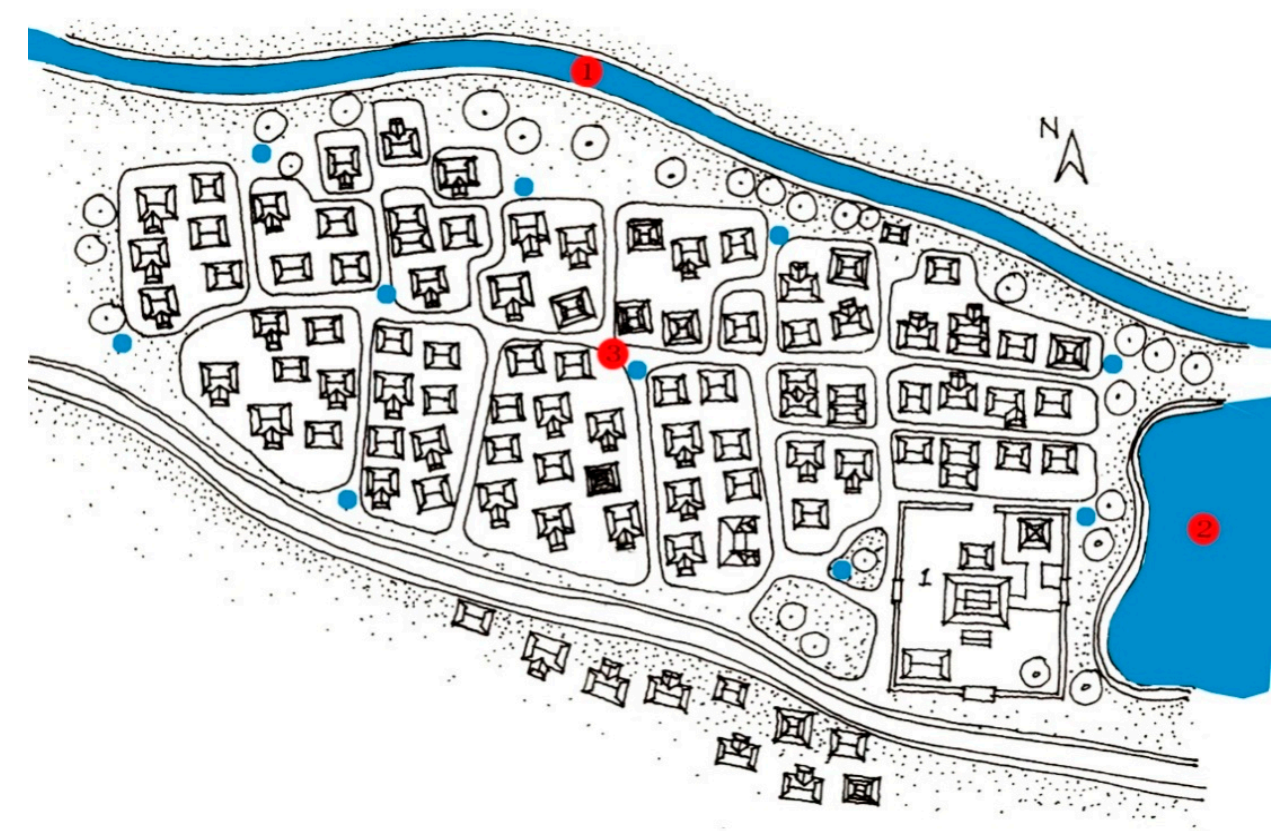

Figure 3. Water Environment Map of Manguanghang Village, Xishuangbanna. 1 is river, 2 is pond, 3 is well [11] (p. 114).

There are two theories about village site selection, namely "stereoscopic distribution theory" and "stratospheric habit theory". Based on the survival status of ethnic groups in anthropology, the "stereoscopic distribution theory" combines the means of production with the living space to strengthen the relationship between the strength of ethnic groups and land form, which holds that ethnic strength determines the stereoscopic form of the occupied land from low to high altitude, while the land form determines the form of the village. "Stratospheric habituation theory" means that the suitability of a population for stratospheric migration determines its destination and the habituation determines its settlement form. "Stratospheric habituation theory" means that the adaptation of a population to the stratosphere determines the destination of its migration and the settlement form is determined by its habituation [20]. The two theories interpret the formation of villages from different perspectives, such as war and ethnic habits, while Dai people prefer to live in a place where people and the environment can coexist sustainably. The spatial layout of Dai villages implies the concept of national culture and construction science. On one hand, site selection and construction pay attention to adapting to local conditions and ingeniously use topography and terrain to achieve the purpose of saving land and manpower and material resources. On the other hand, plane layout and space 
composition emphasize that livability can be achieved by adopting reasonable construction technology and construction measures. The site is located in river valleys and flatland areas, close to the water source and run after the terrain. The use of water sources has become a prerequisite for settlement and survival. Firstly, it is convenient to get water for life and production. Secondly, water evaporation can form an air ecological cycle. The air flow caused by the difference of heat gain between the surface of a water body and the surface of land near water is easy to form a land-water breeze to improve the living environment.

\subsubsection{River Valleys and Flatland Areas, Scientific and Reasonable}

Dai villages are located in river valleys and flatland areas, mainly planting rice, and surrounded by lush forests, which are integrated with the ecological environment. The layout of Dai villages can be divided into two types according to the topographic: flatland type and valley type (Figure 4). The flatland type (Manbie village) has a gentle terrain, broad vision, clear village pattern, and good ventilation in summer, which is conducive to agricultural production and life. The settlement of the valley type (Manla village) is based on the terrain of the valley, where rice, corn, and other crops are planted. The villages are laid out along the terrain and surrounded by rivers, and the fields are in front of the buildings which are embraced as the core. The " $U$ " type of the valley, during day and night, accelerates the flow of air due to the difference in illumination, forming a "river valley breeze", which is conducive to ventilation and heat dissipation.
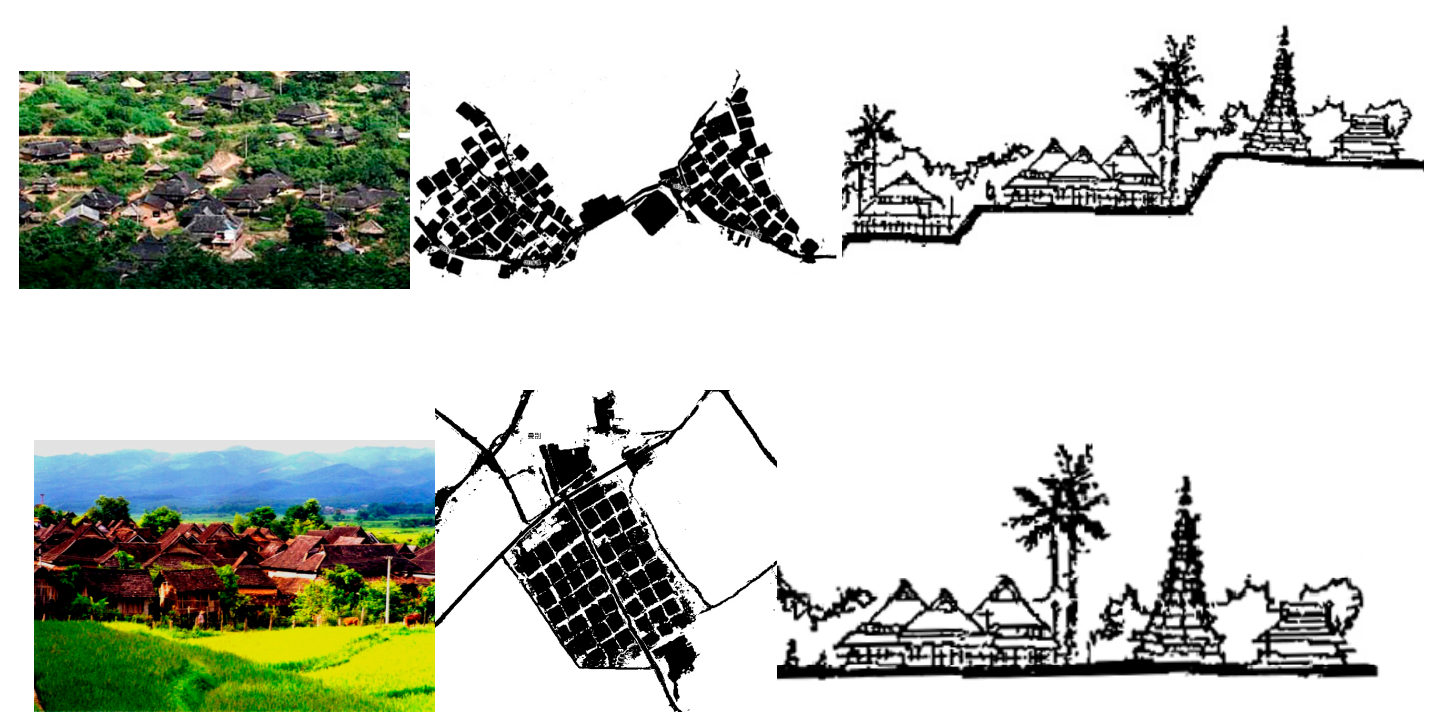

Figure 4. Comparative analysis of valley type and flatland type.

\subsubsection{Site Selection of Villages is Conducive to Agricultural Production}

The ancestors had long planted rice in history and Dai nationality is one of the earliest engaged in rice farming in Asia. In Southwest China, rice culture can be traced back to the Neolithic Age. According to the excavation of archaeology in recent years, the sarcophagus of the Neolithic Age and the bronze urn of the Bronze Age were wide in the blade. From this point of view, the original rice cultivation was paddy farming, that is, rice [21]. Based on the production form of rice farming, the special mode of production of balustrade dwellings will inevitably produce corresponding culture and living forms. In the balustrade dwellings, it directly reflects the characteristics of rice farming ethnic groups. The whole building is composed of houses and balconies. The balconies of Dai balustrade dwellings are designed for life and serve as barnyards. According to the research of scholars, agricultural irrigation for rice planting appeared in Dai nationality area two thousand years ago [22]. Li replaced this central dissemination theory with the theory of plane advancement. He said that "Asian cultivated rice originated from Zhejiang, Fujian, Jiangxi, Taiwan, Guangdong, Guangxi, and Yunnan to the north 
of Vietnam in the South-central Peninsula, Northern Myanmar, Northern Laos, and Assam in India, a vast arc zone" [23]. The location of Xishuangbanna is just at the center of this curved zone: east of Northern Myanmar, west of Northern Laos, and north of Northern Thailand, modern wild rice is widely distributed throughout the state, the relationship of modern Dai rice cultivated species is very close to that of Banna Modern Ordinary wild rice [24]. It is proven that Dai in Xishuangbanna is one of the origins of cultivated rice in Asia. In addition, pattra-leaf scripture records Dai Creation Epic Bata Ma Ga Pang Shangluo and the classic Passatan all have rice records. The name of Xishuangbanna (12 thousand fields) originated from this and has a close relationship with rice cultivation.

Due to the convenient water sources and favorable ventilation, the sustainable ecological environment system for human settlements has been formed. Since ancient times, Dai people have taken rice farming as the main body of agricultural economy. They have a high dependence on water, and the rank of the elements they pay attention to is water, field, and forest. The agricultural civilization is different from the nomadic civilization. Rice farming needs a relatively stable growth environment and a longer growth cycle, so village space suitable for farming civilization emerges as the times require [19] (pp. 132-133). The layout of Dai villages follows the principles of adapting to local conditions and conforming to nature, and chooses ideal habitats with mountains, water, fields, and good natural landscape. With the simple belief in the worship of the mountain and water spirits, the village is placed under the framework of nature and harmoniously symbiotic with natural elements such as landscapes and creatures. This ideal layout, which is based on the earth, mountains, and rivers, produces a sense of security and destiny with the protection of gods and forms the unique environmental image of traditional settlements [25]. Taking respect of the natural environment, freedom layout and suitable survival are the main factors for the location of the village, no matter which kind of village layout is the "mountain-forest-village-water" organic unified ecosystem (Figure 5).

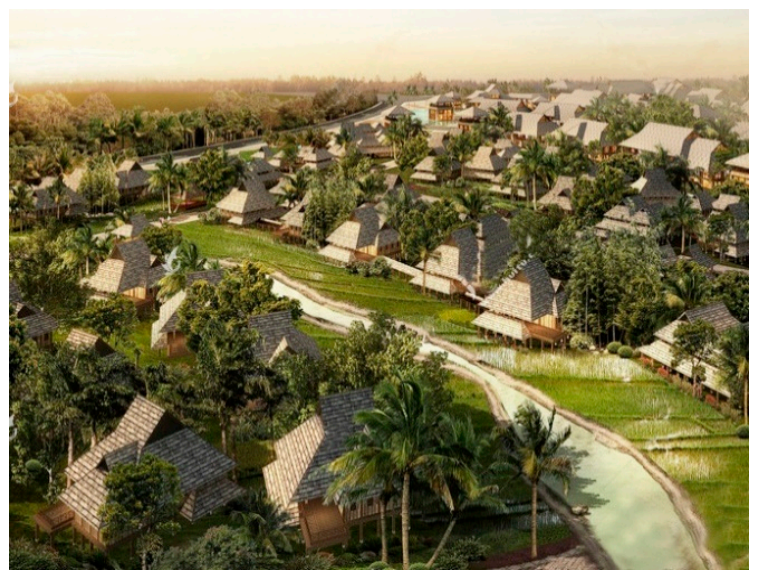

Figure 5. Village layout [26].

\subsection{Spatial Structure of Traditional Dai Villages}

Spatial structure is the internal organization mode and order of the spatial form components. Through the analysis of the spatial structure, the spatial form can be clearly understood and the causes of the formation are explained. No matter how complex the form is, it contains a clear and orderly structure [27]. Different spatial forms may be generated by the same structure. In the study of village space, a clear and orderly and relatively stable structure model is more conducive to the analysis of the factors of village space environment. Fujii considered that the reason why people outside the tribe can visually recognize the spatial composition of the settlement is that the order of geometry can be seen from the spatial composition of the diagram [28]. Dai villages are divided into three parts: upper, middle, and lower, which are built along the river. The east, south, west, and north of Dai nationality are a relative concept, upstream for the north and downstream for the south, which is different from the scientific direction determined by the magnetic field. This is because the rivers in western Yunnan 
flow from north to south. In order to obtain better living conditions, Dai ancestors migrated along rivers and valleys, so the source of the river is north and the flow is south. This simple concept of orientation has deeply influenced Dai people. In settlement, the villages upstream became "up village" or "northern village", and the downstream became "down village" or "southern village".

Dai villages are composed of ancient trees, cemetery, gates, pagodas, temples, heart of villages, dwellings, roads, wells, ponds, and so on (Figure 6), which are established in a certain order and each element has its specific spatial significance. According to the inner and outer space of Dai people, cemetery, ancient trees, and gate belong to the outer space, while the heart of the village, building, roads, wells, and ponds, belong to the inner space.

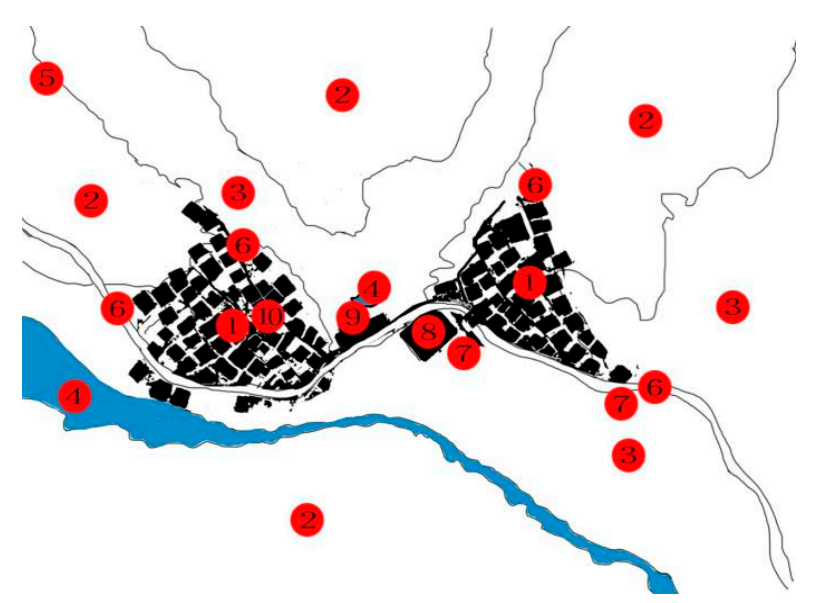

(a)

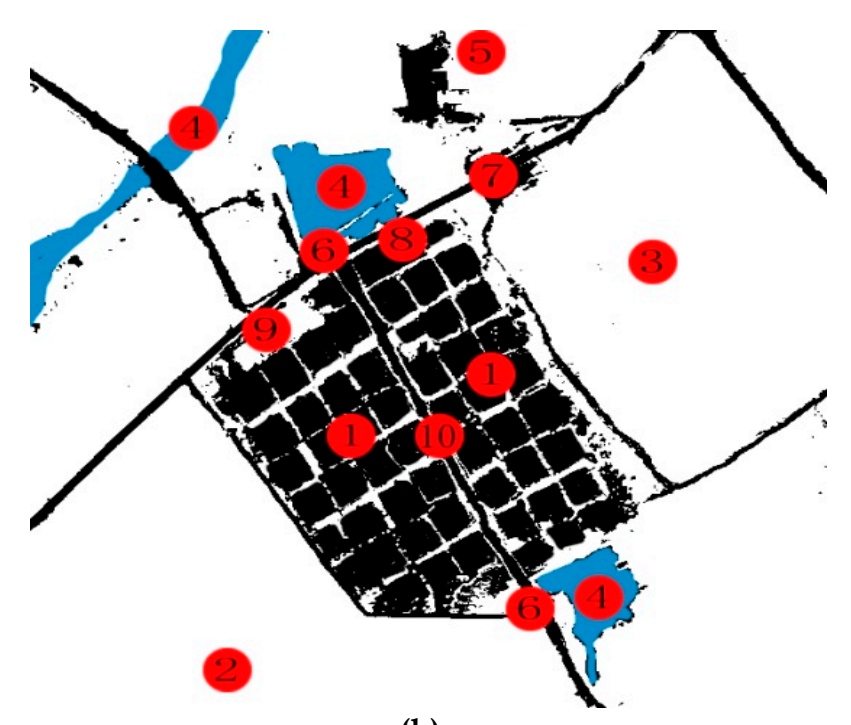

(b)

Figure 6. The composition of Dai villages. (a) Manla village, (b) Manbie village1 is folk, 2 is forest, 3 is filed, 4 is water, 5 is grave, 6 is village gate, 7 is tree, 8 is pagodas, 9 is public activity space, 10 is village heart. (self-drawing).

\subsubsection{Village Gate}

After the location of Dai village is determined, the most important activities are "set up village gate" and "establish village heart". The village gate is commonly known as "muduman" in Dai language, which is the spatial definition sign of "inside" and "outside" of the village. The village gate is the first space node to enter the village, and the setting method and spatial composition elements reflect Dai residents' perception of the boundary space nodes of the village. The village gate is generally set up on the main roads in the four directions, which is intended to prevent disasters and evil spirits, 
and to protect the family members who enter and exit the gate of the village [19] (p. 133). The village gate is the "definition" of the village space, which contains the color of primitive religion, and is the boundary between life and death, people and "ghosts". The shape and structure of the village gate changed from simple two wooden pillars pulling a beam in the early stage (Figure 7a) to complex and golden color (Figure $7 \mathrm{~b}$ ) in the later stage by the influence of Southern Buddhism. The change of the village gate shape also reflects the transformation of Dai people's faith from the primitive religion of the nation to Buddhism. The function of the village gate is defined by the original village space, which is transformed into the idea to strengthen the regional consciousness and national cohesion.

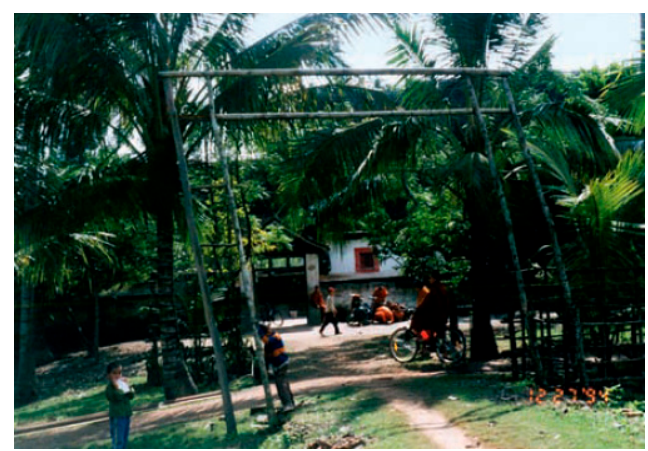

(a)

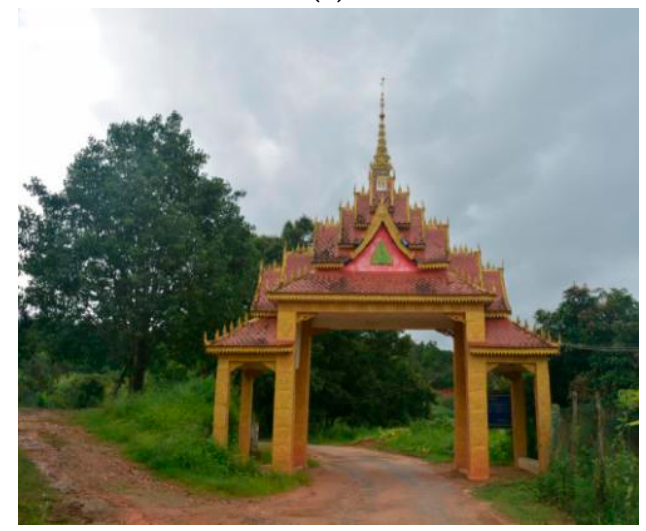

(b)

Figure 7. The evolution of village gate of Dai nationality. (a) The village gate in the early stage [29], (b) the village gate now.

\subsubsection{Ancient Trees}

There are ancient trees around the gate of the village and the Buddhist temple. Dai people believe in "animism" and believe that all things in nature have spirituality, such as trees have tree gods to protect the village, so cutting down trees at will is not allowed. Secondly, the growth of trees is a symbol of local soil and climate. Inspired by the thinking habits of "heaven-human induction", Dai people believe that the local ethnic groups will also flourish where trees are flourishing. Therefore, they attach importance to the planting of trees, and the importance of ancient trees in Dai culture is similar to the "Fengshui forest" in the traditional culture of the central plains. Up to now, the Bodhi and Bayesian in Dai villages are still regarded as divine trees, which are the predecessor of the Fengshui tree in the traditional Dai settlements, and contain multiple cultural meanings such as the village ecology and Fengshui.

\subsubsection{Wells and Ponds}

Water is an important part of Dai culture and a symbol of cleanliness, auspiciousness, and life. Dai people live by water, engage in rice production, and pay attention to the protection of the ecological environment, regarding water as a source of wealth, and distribute wells and ponds all over the village. 
The pond is an important part of the village space environment, which can not only effectively adjust the local microclimate, but also feed fish and ducks. In terms of spatial relationship, ponds play a role in defining the space of residential buildings, which is conducive to dispersing the spatial layout of residential buildings, keeping a certain distance between residential buildings, facilitating ventilation and lighting. The well is the main source of water for the family, and wells environment is particularly important in Dai culture. The spatial layout of wells is common with ancient trees and bamboo forests, which plays an important role in the life of Dai people and reflects Dai culture's worship and emphasis on water.

\subsubsection{Heart of the Village}

Heart of the village is also called "Zaiman", which is located in the center of the village and has a sacred status in the village. It is the soul of a village and the core of space and spiritual origin, as well as the "materialized" spiritual symbol of the original faith, blessing the peace of a village. The form of the village heart is diverse. Some are one or several wooden piles, and some are placed with one or a few stones. The specific shape is not fixed, which can be a stone, a big tree, or another symbol. The village heart is the symbol of the life of the settlements and also the symbol of the collective cohesion. The village heart sacrificial activities are held in March every year of the Dai calendar. In the main road of Dai villages, the village heart presents a "cruciform" distribution (Figure 8). The spatial layout of Dai villages presents a radial distribution with the village heart as the center.

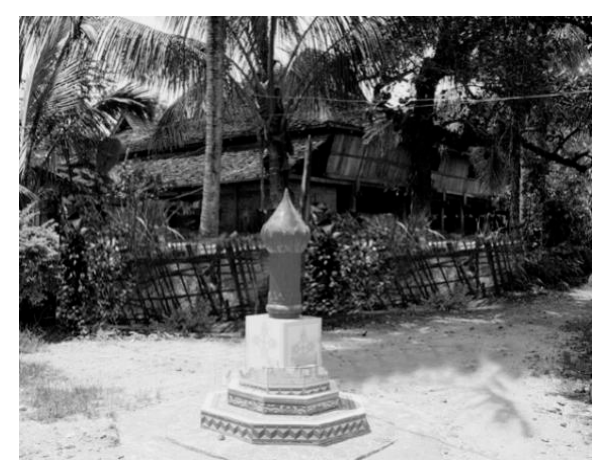

Figure 8. Heart of the village.

\subsubsection{The Buddhist Temple}

Dai people believe in the Southern Buddhism, Buddhism culture plays an important role in Dai culture. There are many temples and pagodas in countries, where there is a village there is a temple, a pagoda, and however many villages there are, there are as many towers [30]. Scholars considered that the Southern Buddhism was introduced into the Yunnan Dai ethnic in the early 13th century and was believed by Dai people. The temple (Figure 9) is the center of the cultural life of Dai people. The function of Buddhist temples is similar to that of Han schools and the peaceful and kind national character of Dai nationality are not only related to ecological environment and natural resources, but also deeply influenced by Buddhist culture. The spatial layout of Dai villages contains rich and colorful religious culture. Buddhist Temple facilities should be built first when constructing villages, as religious culture determines the appearance of villages. As long as there are Dai villages, there are Buddhist temples. Buddhist temples are called "Zhuangfang" and "Myanmar Temple" in Dai language and people living in the same area for generations have common beliefs and have a strong sense of identity with national culture. Dai Buddhist temple architecture is an important part of the layout of Dai people's settlements and is usually located in the most prominent part of the settlement. According to the geographical situation of the settlement, the Buddhist temple is usually located at the entrance of the settlement or the center of the village [19] (p. 133). The structure of the Buddhist temple is the most prominent in the layout of the entire village. The layout of residential buildings should be mainly Buddhist temples, and should not be higher than them. 


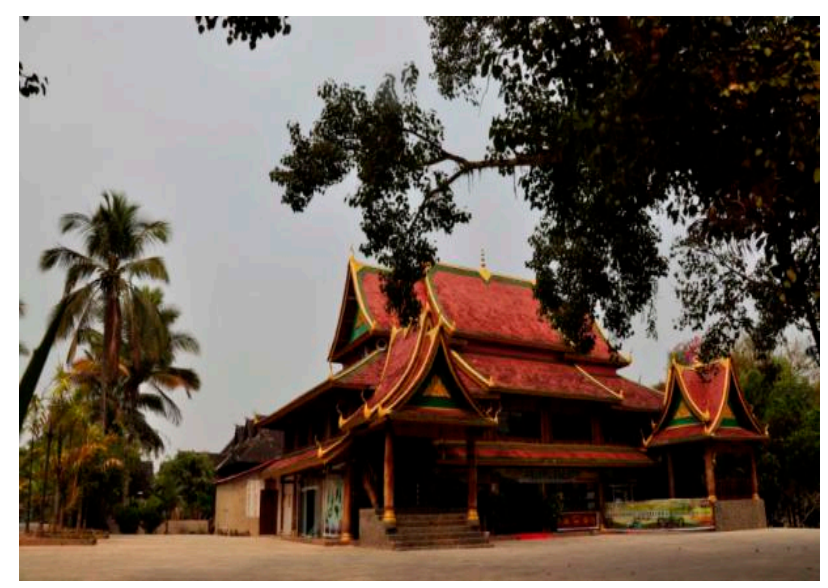

Figure 9. The Buddhist temple.

\section{Analysis}

\subsection{Ecological Philosophy of the Unity of Nature and Man}

Dai nationality is one of the earliest "rice-growing" nationalities and the villages have the following characteristics according to the requirements of "rice-growing culture": firstly, the location of the village site should have good interaction with the rice cultivation area, and the water body and farmland cultivation are the primary factors for consideration, while the full use of water proves that Dai people like water. Secondly, the living habits of "living in the same clan" make the layout of villages have a good order, which is defined as the spatial order for the purpose of convenient farming, production, and life.

The ideological foundation of Dai people's traditional villages' living environment is as follows: cognition of heaven, earth, and human relationship caused by primitive chaos, thinking objective creation activities guided by practicality-interpretation of divine ideas and pitching-in - the formation of the pattern lay equal stress on "theory" and "material". The formation of the pattern determines the purpose of human settlements for practicality and the symbolic element of the spirit. Therefore, the material of the traditional villages of Dai people presents ecological, purposeful, and symbolic meaning of the cultural image of the nation. Dai people regard the natural world as a whole, while the existence of the village cannot destroy the integrity of the natural world. The integrity and coexistence of nature all become the basic understanding of Dai people to the natural world. The space of nature is the unity of harmony and symbiosis. The coexistence of all things is Dai people's understanding of space use. The traditional villages of Dai nationality strive to construct a natural ecosystem with holistic and coexisting elements.

Vitality adapted to nature. Dai people live in subtropical jungles that are hot and humid, rivers crisscross, forming a harmonious system of symbiosis between human and natural environments. Dai villages have been continuing the true beauty of nature, which is inseparable from their long-term natural survival experience and the natural ecological concept in Dai culture. Villages are closely related to people and social life. On one hand, villages are understood as the combination of common people in life events, on the other hand, villages are implicit in the social lifestyle and structure of human beings in the tangible material space form. It can be seen that comprehensiveness is the basic characteristic of the village itself, including the integration of human, nature, and society, the integration of function and structure, the integration of human living behavior and construction behavior, and the integration of material and non-material form elements [31]. The ecological philosophy of Dai people's harmony of nature and man is a kind of sustainable expression, which includes the continuity between man and animals, between earth and heaven, between culture and nature. Dai people believe that animals and plants are alive. Peacocks symbolize good luck and elephants symbolize rich grain in their life. Hunting and tree-cutting are killing behaviors, which should be strictly controlled. The traditional cosmology 
of man and nature blending together and primitive religions believed in animism of Dai people are manifested in the view of sustainable ecology, that is take it in moderation and use it sparingly.

\subsection{The Human Settlement Ecology View of the Integration of Primitive Belief and Buddhism}

\subsubsection{Primitive Worship}

First, the god of nature worship. Natural disasters are difficult to overcome, so they have the original consciousness of nature worship. For example, clouds or thunder in nature lead to precipitation, and the amount of precipitation is not controlled by human ability. In particular, excessive precipitation leads to flood, which is difficult to predict or change. Thus, the worship of god of nature comes into being. The awe and worship of cloud god, thunder god, and water god are more popular in Dai people.

Second, the consciousness of ancestor worship. In the concept of "animism", man is god after death. Ancestors would bless their descendants in another world, and their inns are endowed with spirituality. They worried that someone would destroy them intentionally and lead to the good luck disappears, which could affect their descendants. The latter, such as the cemetery, reflects the simple awareness of ancestor worship. Dai people believe in "animism". They believe that nature is the source of human life and the one on whom our livelihood depends. So far, Dai people still have the custom of tree god belief in their settlements. Each Dai settlement has one or more trees with luxuriant branches and leaves and shady green trees, which are regarded as divine trees and incense is offered under the trees, and they are located in the prominent position of the settlement, which is a symbol of the prosperity of the settlement [19] (p.133). The simple primitive thinking of Dai people embodies the idea of harmonious coexistence between man and nature and the sustainable ecological concept of treating natural resources with "reasonable access and appropriate use". The principle of moderation and harmonious coexistence should be adopted because if the natural world is seriously injured, the extinction of certain natural things will inevitably lead to human survival falling into a certain predicament [32].

Dai culture retains the typical original cultural characteristics, which permeates into culture, art, daily life, and other aspects. The site selection of the village is first reflected in the ecological nature, and it is less active in transforming the topography and destroying the natural ecology, so as to maintain the harmonious relationship between man and nature, and shows the religious thought of the original religious belief, reverence, and worship of nature, and co-habitation of people and gods. Dai people have always held a respectful attitude towards nature. The philosophy of Dai people holds that nature is the one on whom our livelihood depends, the forest for the father, the earth for the mother, hoping to get more benefits from nature. Dai dwellings are adapted to the natural environment. The layout of the villages is adapted to local conditions and topography and the building materials are derived from local natural resources. The building and the local natural landforms are integrated into one, which is an organic part of nature. Dai villages contain the philosophical concept of "harmony between man and nature". All activities of people in the natural environment should follow the laws of nature, and the relationship between man and nature should be harmonious and symbiotic. As Dai people's ballad sings, "If there is forest, there will be water to irrigate farmland, if there is field, there will be food, and if there is grain, there will be Dai family. The earth is mother, the forest is father, and only from parents can we get food". Why do Dai songs use the metaphors of flowers, animals, stars and moons, wind and clouds, mountains and rivers? Any kind of song could not do without these metaphors. The main reason is that ancestors of Dai people were born in the forest and the banana forest. They were songs given by birds and water. As soon as Dai songs were born, flowers and leaves were clothes, nebulae, sun, and moon were ornaments, deer and birds were partners, so Dai songs could never be separated from them [33]. The ecological thought is the sustainable ecological view that people and natural environment coexist. 


\subsubsection{Spatial View Influenced by Southern Buddhism}

Genius loci is the idea of Rome. According to the ancient Roman faith, each "independent" body has its own genius. The spirit of guardian God gives life to people and places, accompanies people and places from birth to death, and determines their characteristics and essence. The fact that even the gods have their own gods illustrates the main essence of this idea [13] (p. 18). After the introduction of Southern Buddhism into the Dai area, it was combined with Dai primitive religion. The whole Dai people believed in Southern Buddhism, which was embodied in Dai villages, Buddhist temples, architectural layout, and shape. Form is not merely a contour and a shape, but the set of levels, changes, and relations that make everything a thing-form becomes the life, soul, and direction of the object. Form is external display. Form and the internal complement each other and rely on each other [30] (p. 85). Dai people regard space as "square", that is the spatial cognition of Dai villages, which is influenced by Southern Buddhism. Mandala, a graphic from ancient India, is used by Hinduism and Buddhism. Mandala symbolizes a tired human body, with its center at the umbilicus. Mandala's planar schema contains square and circle, which is a four-in-one structure, or a multiple of four, in the form of square and octagon.

It is generally believed that the figure of Mandala appears in the Buddhist Secret Sect, and the actual study shows that Southern Buddhism is also deeply influenced by Mandala. Southern Buddhism is heavily influenced by Mandala, and the use of Mandala ritual in Southern Buddhism is so extensive that it is compared to doing everything with Mandala before taking action [34]. Mr. Wu said: "in the Vedic Age of ancient India, people have used Mandala for the planning and design of individual buildings, architectural groups, even villages, towns, and cities, and expressed their views on the universe to make buildings, towns, and cities have various symbols, schemata, and symbolic significance." Buddhism has inherited the traditional culture of India, and the architecture adopts Mandala schema to express the cosmology and philosophy of Buddhism [35]. Influenced by the space concept of Southern Buddhism, Dai people deduce the cognitive figure with "square". In an ideal geographical environment, the overall layout of the settlement is square or approximately square (such as Manhai and Manbie), and only under the influence of topography and landform can spatial shape be deduced. Buildings (Buddhist temples, folk houses) are less affected by the terrain, so they are the standard "square" from the plane. "Square" is also applied in clothing, brocade, and other decorations after deduction.

Dai nationality has evolved into eight spatial directions according to the four directions of east, south, west, and north. Each direction has specific symbolic animal and specific meaning. The Shan people in Myanmar share the same belief in animal and direction. In Dai architectural space concept, people live in the east and the land is in the north as well as the forest is in the south and the water is in the west. The East points to the place where people live, which symbolizes life, is the sacred direction and the direction where the sun rises. It has formed a national ecological concept that advocates nature, respects ecology, and combines Southern Buddhism (Figure 10).
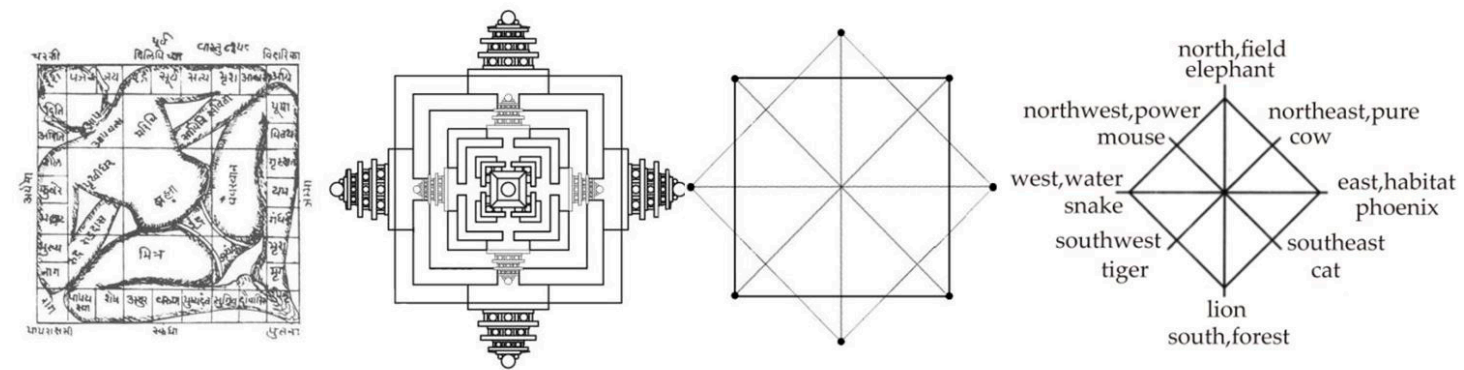

Figure 10. Deductive diagram. 


\subsection{Multivariate Space Constructured by a Single Ethnic Group}

The geographical features of Dai villages are relatively closed, and the ethnic structure is single, which makes Dai villages less affected by the outside world. Compared with the villages in other places, the existence and continuation of Dai villages has the characteristics of independence, ecology, integrity, and continuity, and the development process is mainly influenced by multiple factors of the nation. The traditional factors are expressed clearly and completely in the form, structure, space, architecture, nature, culture, and social environment of the settlement, and can comprehensively and systematically reflect the corresponding characteristics of the village and architectural space. Dai villages are influenced by three factors, e.g., natural environment, religious belief, and social environment. The rich and varied spatial composition and elements include three levels, e.g., human settlement field, production field, and spiritual field (Figure 11).

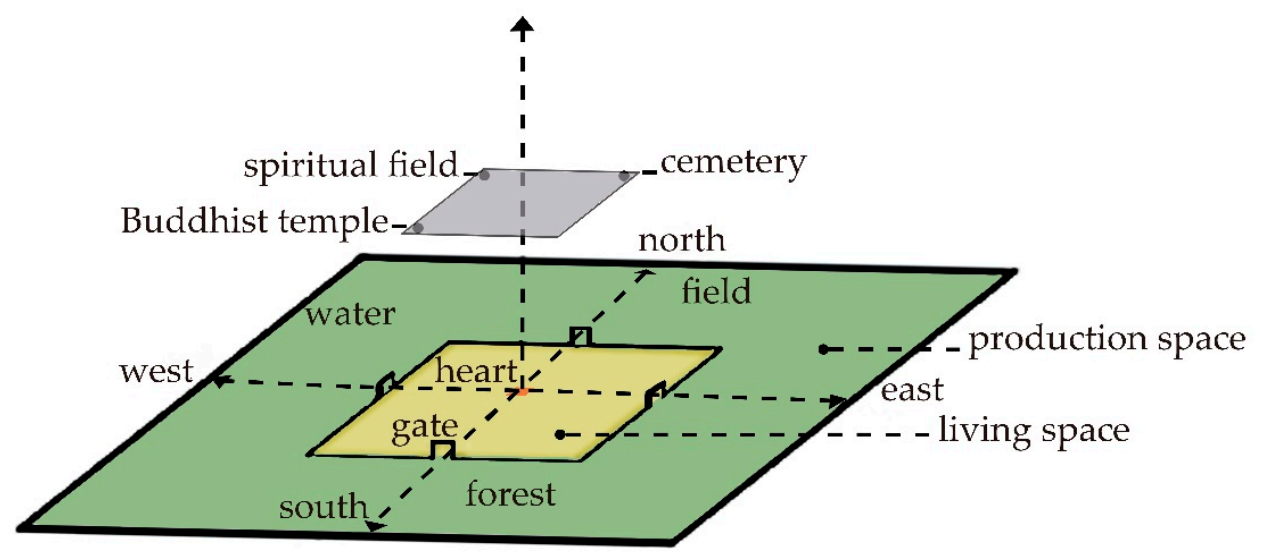

Figure 11. Spatial hierarchy.

"Since the birth of mankind, every member of the human race has lived in the natural environment of a certain climate, terrain, flora and fauna zone from the moment he was born, and also entered a cultural environment composed of certain beliefs, customs, crafts, artistic expressions, and so on" [36]. The living space environment of Dai villages is an organic unity of production, living environment (human settlements, production fields), and belief (spiritual fields) to satisfy their own survival. In the spatial layout of Dai villages, village heart, village gate, temple, Longlin, field, forest, and water, are important elements. Village heart, village gate, temple, and dwelling house constitute the human settlements, and village heart is the soul of the village. Each of the four directions of the village has a village gate which is the space defining object between the village and the outside, as well as the symbol of the inside and outside of a village. Village heart and the village gate form a cross-shaped distribution of the main roads of Dai village. Forests, water, and fields constitute Dai people's production area. Sustainable development of human and nature is Dai people's ecological view, and forests and rivers are the important factors for village site selection. "The forest is the father, the earth is the mother, all things grow in the earth, and forests breed all things." As Dai proverb says, "Without a river, you can't build a country, without forests and mountains, you can't build a village." [37]. Dai village is located in the valley and basin area, adjacent to the forest, the river passes through the basin area, and the surrounding village is suitable for planting rice. Dai people are traditional rice-cultivating people. The growth of rice is inseparable from the water source. Rivers are the main irrigation water source. Secondly, the surrounding forests have the functions of conserving water sources, creating an environment and regulating local climate. The spiritual field reflects the influence of primitive religious worship and Buddhist belief, which is manifested in temples and Longlin. The Buddhist temple is located in a prominent position in the village and is the center of the activities of Dai people. It is for Dai people to study Buddhism and Buddhism. Longlin is equivalent to the graveyard of the Han nationality, located in the woodland near the village, higher than the village elevation. Dai nationality 
is a cremation nation. After the death of Dai people, they were burned in Dai forest with the help of the people. No graves were set up. After the burning, they were washed by rainwater and returned to nature. This reflects the sustainable ecological concept of harmony and interdependence between Dai people and nature.

The ecological and cultural sources of human settlement in Dai villages are accessed from two aspects: one is the simple primitive belief, which pays attention to the ethnic consciousness of the unity of heaven, earth and man, and the other is the culture brought by Southern Buddhism. The integration of the two cultures makes the growth mechanism of the village appear as a central divergence type and a perimeter definition and the commonality of the two types is reflected in the fuzzy area of the reserved space, showing the human settlement spirit considering the ecological bearing capacity. The village space is guided by the cultural core of the crowd, which can be presented with materials. The sustainable ecological environment of Dai villages is reflected in the suitability and ecological inclusiveness of the village site selection. The village space is constructed by both material and non-material, and is influenced by the multi-integration of space and ecology. The village heart should be built before the building of the village. The village heart is the symbol of the original religious belief of the nation and the center of the spatial meaning of Dai village. The residential buildings are scattered around the center of the village (Figure 12a). The Buddhist temple is the material carrier of the Southern Buddhism beliefs and is generally located in the most prominent position of the village, or the center of the collective spiritual exchange of the villagers and the distribution center of public activities (Figure 12b). The village heart and the Buddhist temple form the village pattern in which the two core points of the same ethnic group coexist. Dai villages are an artificial system embedded in the natural environment, and the ecological space of the village carries the production and life of Dai people. The emergence of Dai villages is the result of the interaction between the natural environment and the social structure, religious belief, family organization, and production mode of the nation.

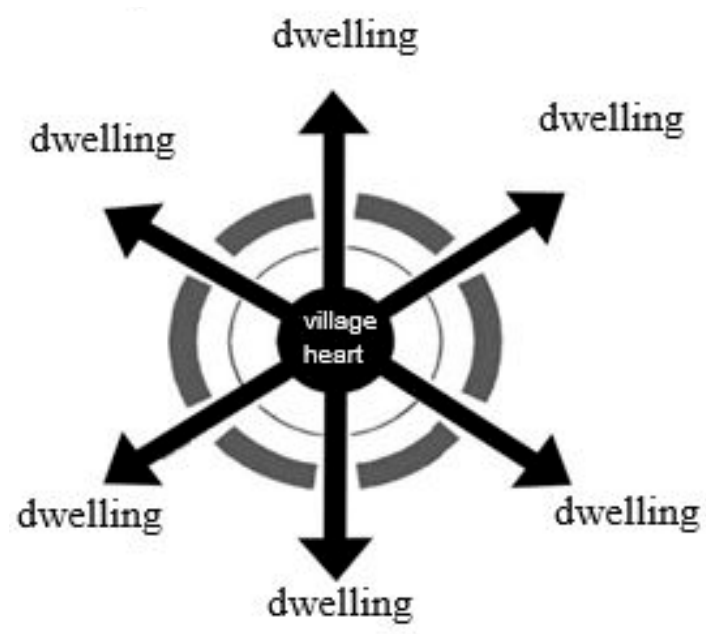

(a)

Figure 12. Cont. 


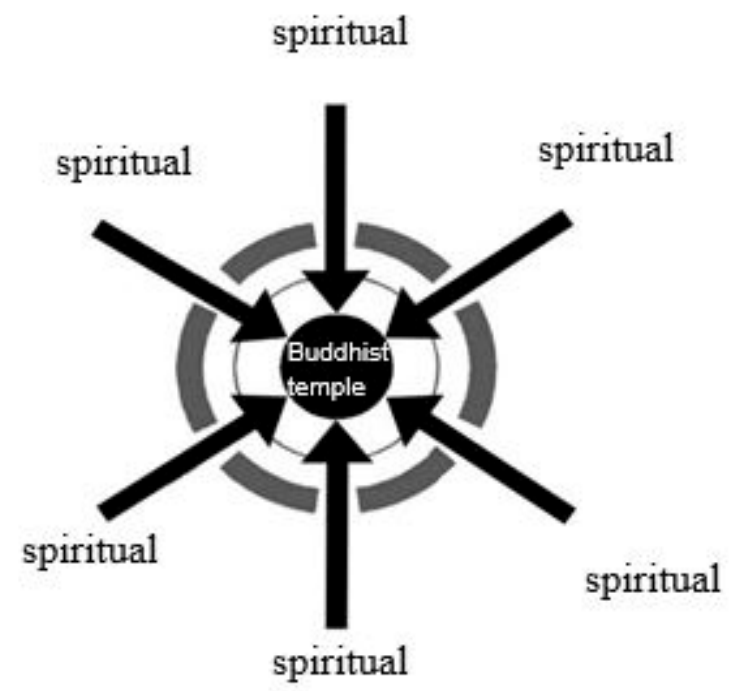

(b)

Figure 12. Village forms with two cores of an ethnic group. (a) Dwellings are scattered around the heart of the village, (b) a center of spiritual exchange.

\section{Conclusions}

Dai villages are the place where the ancestors of Dai people live, produce, and collectively construct human settlement, production, and spirit. It has retained the way of harmony with nature so far. They are excellent architectural and cultural heritage with important historical value, cultural value, scientific value, artistic value, and tourism resource value. Dai villages are the sustainable ecological wisdom formed by Dai people in the process of adjusting to nature, which has local and national characteristics and harmonious coexistence between man and nature. Including Dai's cosmology, mode of production, lifestyle, religious beliefs and customs, the spatial pattern of "water-forest-field-village" and the elements of the village are deeply influenced by Dai's ecological and cultural concept of harmony between man and nature, human settlement ecology view of the integration of primitive belief and Buddhism. This paper discusses the ecological concept of sustainable development contained in the living space environment of Dai villages, and explores the ecological concept and precious experience of Dai people compatible coexistence with environment. It has important reference function for how to maintain the relationship between human and environment, culture and nature, and has important academic value and application value for the current sustainable development theory of human settlements space environment in traditional villages.

Author Contributions: All authors contributed to the paper. H.-f.W. wrote the manuscript with the supervision from S.-c.C., and H.-f.W. acted as a corresponding author.

Funding: This research received no external funding.

Acknowledgments: Thanks for the help of Xue Ai, Wen Ai, Hong Yu and Yan Ai etc. Especially grateful to Xue $\mathrm{Ai}$, he has given us an enthusiastic reception, recommended interviews, accompanied inspections and provided detailed introductions. We sincerely thank the anonymous reviewers for their detailed and valuable suggestions for revision.

Conflicts of Interest: The authors declare no conflict of interest. 


\section{References}

1. Xiong, M.J.; Guo, J.H. Study on the present situation and development mode of tourism in ancient towns in southwest China. Philos. Soc. Sci. 2007, 26, 75-78. (In Chinese)

2. Forestry Bureau of Xishuangbanna. Forestry Records of Xishuangbanna Dai Autonomous Prefecture (1978-2005); Yunnan National Publishing House: Kunming, China, 2011; p. 29. (In Chinese)

3. Xishuangbanna National Nature Reserve Administration. Xishuangbanna National Nature Reserve; Yunnan Education Publishing House: Kunming, China, 2006; pp. 21-24. (In Chinese)

4. Wang, L.L. Space Analysis on the Yunnan Nationality Settlements: Take Three Villages for Example. Ph.D. Thesis, Wuhan University, Wuhan, China, 2010. (In Chinese)

5. Wang, Q. Traditional Fortress Settlements: A Case Study of Qin and Jin Area. Ph.D. Thesis, Tianjin University, Tianjin, China, 2004; p. 28. (In Chinese)

6. Zhang, G.Z. A Study of Settlement Pattern Archaeology; Six Lectures on Archaeology; Cultural Relics Press: Beijing, China, 1986; pp. 74-93. (In Chinese)

7. Jiang, Y.L. History of Dai Nationality; Sichuan National Publishing House: Chengdu, China, 1983; pp. 1-8. (In Chinese)

8. Yang, C.M. Architectural Culture of Minority Nationalities in Southeast Asia and Southwest China; Tianjin University Press: Tianjin, China, 2004; pp. 2-9. (In Chinese)

9. Liu, Y. Study on Dai Nationality's Ecological Environment Thought. Master's Thesis, Yunnan Normal University, Kunming, China, 2007. (In Chinese)

10. Shan, J. Regionality of Architecture and City-A Study of Regional Architecture Based on the Concept of Human Settlements. Ph.D. Thesis, Tsinghua University, Beijing, China, 2001. (In Chinese)

11. Gao, Y. Dai Dwellings in Yunnan, China; Peking University Press: Beijing, China, 2003; pp. 2-10. (In Chinese)

12. Zhou, J.F. Study on the Landscape of Dai Traditional Villages in Dehong Area, Western Yunnan. Master's Thesis, Huazhong Agricultural University, Wuhan, China, 2010. (In Chinese)

13. Schulz, N. Genius Loci: Towards a Phenomenology of Architecture; Huazhong University of Science and Technology Press: Wuhan, China, 2010; pp. 18-21. (In Chinese)

14. Fu, S.H. Projection of Primitive Religious Concepts on the Space of Traditional Dai Villages. Theoretical Realm 2010, 1, 146-147. (In Chinese)

15. Li, J.H.; Zhang, X.G. From Residential Buildings to Settlements: A New Trend in the Study of Regional Architectural Culture in China: A Case Study of Southwest China. Archit. J. 2010, 3, 83. (In Chinese)

16. Guo, Z.L. Settlement and Society; Rural City Publishing House: Taipei, Taiwan, 1998; p. 69. (In Chinese)

17. Wang, X.L. Anthropological fieldwork: Seeking law in interpretation. Ethn. Study 2002, 5, 40-42. (In Chinese)

18. He, X.L.; Guo, H.Z. A Brief Discussion on the Innovation of Ethnography Methods in Anthropology. Thinking 2014, 40, 7. (In Chinese)

19. Wang, H.F. Interpretation of Dai folk dwellings from the perspective of plastic art and space composition. Southwest. Front. Ethn. Stud. 2012, 1, 134. (In Chinese)

20. Lin, X.D. On the three-dimensional distribution of folk dwellings. New Archit. 2011, 3, 114-118. (In Chinese)

21. Sarano, K. The Source of the Japanese Nationality_Yunnan; Yunnan People's Publishing House: Yunnan, China, 1985; p. 1. (In Chinese)

22. Li, K.S. The Status of Yunnan in the Study of the Origin of Rice Cultivation in Asia. Soc. Sci. Yunan 1981, 1, 71. (In Chinese)

23. Huang, H.H. Form Yue People to Tai People; Yunnan National Publishing House: Kunming, China, 1992; p. 6. (In Chinese)

24. Yang, D.H.; Xiao, D.W. Reconstruction of power-transmutation of traditional villages and construction of new countryside. Huazhong Archit. 2012, 11, 141-144. (In Chinese)

25. Gao, L.S. Long-standing rice culture of the Dai people. J. Kunming Teach. Coll. 1999, 1, 72-76. (In Chinese)

26. Huaban. Available online: http://www.nipic.com/detail/huitu/20160421/171233153200.html (accessed on 16 July 2019). (In Chinese)

27. Li, D.Z. Introduction to Environmental Behavior; Tsinghua University Press: Beijing, China, 1999. (In Chinese)

28. Fujii, A. Settlement Visits; China Building Industry Press: Beijing, China, 2003; p. 20. (In Chinese) 
29. Feng, X.; Yamazaki, J. Study on the spatial structure of traditional settlements based on the method of living place names: A case study of the Mmanhai settlement in Xishuangbanna, Yunnan province. Urban Plan. Int. 2017, 32, 72-78. (In Chinese)

30. Jiang, G.C. Yunnan Ethnic Housing Culture; Yunnan University Press: Kunming, China, 1997; p. 148. (In Chinese)

31. Tang, Y.S.; Zhu, C. The Characteristics of the Southern China's Traditional Settlements and the Design of the GIS System. J. Hengyang Norm. Univ. 2003, 24, 13-18. (In Chinese)

32. Yu, X.D. The origin of ancient Chinese ecological culture. J. Jiaxing Coll. 2000, 1, 9-14. (In Chinese)

33. Gu, B.M. On Dai Poetry; China Folk Literature and Art Publishing House: Beijing, China, 1981. (In Chinese)

34. Lv, J.F. History of Secret Religion in China; China Social Sciences Press: Beijing, China, 1995; p. 48. (In Chinese)

35. Wu, Q.Z. Mandala and Buddhist culture (part 2). Tradit. Chin. Archit. Gard. 2000, 6, 32. (In Chinese)

36. Leslie, W.; Cao, J.Q. Cultural Science; Zhejiang People's Publishing House: Hangzhou, China, 1998 ; p. 82. (In Chinese)

37. Fan, Q.; Zhou, B. The creation of the traditional living environment of Dai people under the influence of religious culture. Natl. Forum 2016, 9, 64. (In Chinese)

(C) 2019 by the authors. Licensee MDPI, Basel, Switzerland. This article is an open access article distributed under the terms and conditions of the Creative Commons Attribution (CC BY) license (http://creativecommons.org/licenses/by/4.0/). 